\title{
Chopsticks as a Typical Dayak Borneo Weapon
}

\author{
Hamid Darmadi \\ \{haamiddarmadi@gmail.com\}
}

IKIP PGRI Pontianak

\begin{abstract}
The ancestors of the Dayak tribe who live amid dense forests and inhabited by various wild animals, inspire and motivate the Dayak tribe to make reliable weapons that are not only able to protect themselves from the fierce forest life, but also able to sustain the existence of the Dayak tribe as a whole. The ferocious wilderness of Borneo island has tapered the determination and enthusiasm "Dayak ancestors make" Typical "weapons called" chopsticks. "Chopsticks are made of iron wood (ironwood). Chopsticks have a length of 1.5 to $2 \mathrm{~cm}$. The best size for a chopstick Chopsticks consist of three main parts, namely: Chopsticks, chopsticks (damak) and chopsticks (spear made of selected iron tied to the end of the chopsticks). Chopsticks that rely on this blowing power, has a shooting accuracy of up to 200 meters, effective shooting distance of 25 to 30 meters to "typical" which makes the chopstick gun deadly because at the end of the dam is spiked / smeared poison in the form of gum ipuh and a mixture of deadly animals that are said to have no antidote. with the advent of Technology and Knowledge, chopsticks began to be rarely produced as weapons of war, but more at p production as a sports tool to clot and order.
\end{abstract}

Keywords: Typical Dayak Weapon Chopsticks

\section{Introduction}

\subsection{Background for making Chopsticks Weapons}

Living amidst a dense forest with tree trees that looms high and is inhabited by various wild and wild animals, has inspired Dayaks to make weapons that are not only able to protect them from the fierce forest life, but also able to sustain their lives both materially and moral. Based on the conditions and objectives of the Dayak people made special weapons, one of them is a weapon that is considered quite unique which is then better known as "Chopsticks".

Chopsticks are typical Dayak tribal weapons which consist of three parts, namely: Stems (chopsticks, Damak (chopsticks) and sangkoh (spear eyes made of or mountain stones tied to the end of a chopstick pipe). effective target from a distance of 25 to 30 meters both vertically and horizontally depending on the ability of the clipper.

With this weapon, Dayaks can knock out enemies and good game animals on trees such as birds and wild animals that live on land from relatively far distances. With the ability of animals and enemies from a distance, the people of Kayak have created quite sophisticated selfprotection tools. If it turns out that the first shot does not hit the target, and vice versa wild animals or enemies strike back at close range resulting in damages can not be used effectively or do not have time to install damak then chopsticks made of wood with a sangkoh are very useful weapons yourself at close range. The existence of a trumpet at the end of a chopstick pipe 
is like a bayonet at the end of a rifle or a spear eye that is ready to be used in the event of an enemy attack.

To make the chopstick's effectiveness more effective, especially for the purpose of hunting or fighting enemies, the orange Dayak smears damak with poisons made from plant sap. According to the story of poison on damak (chopstick children) there is no antidote, so that animals or humans exposed to this weapon even if only scratched can cause death. Which is very unique and difficult to think about by the mind of a dead animal affected by this weapon, the meat is non-toxic and safe to eat (Kompas December 24 204). In addition to the range and the poison which is quite deadly, another advantage of this tool is when it is used it does not cause sound / sound. This silent element is very important when targeting game or enemies who are off guard. Apart from hunting and fighting, chopsticks are also used for traditional equipment or as dowry in Dayak marriages. (Kompas, December 24, 2004).

In line with the changing times and changing patterns of thought and natural conditions where the Dayaks lived, it turned out to influence the existence (existence) of chopsticks as weapons. Chopsticks are gradually being abandoned by the Dayaks and it is not impossible that the weapons with sufficiently high value values will sooner or later become extinct. Therefore preservation measures need to be taken so that the traditional equipment which is a typical weapon of the Dayak is still maintained. This is what drives the writer to improve this problem as a study entitled: "Chopsticks as Typical Traditional Weapons of Dayak Protected High". (Study of Local Wisdom Documentation for Traditional Dayak Traditional Weapons of Borneo)

\subsection{Identification of problems.}

Based on the description in the background of the research above, the identification of this research problem was formulated as follows:

1. Low enthusiasm for the desire of the young Dayak generation to preserve chopsticks as a traditional Dayak weapon both passively and actively in living in a society

2. Low enthusiasm for the desire of the Dayak young generation to preserve chopsticks as passively traditional Dayak weapons, duplication and replication of chopsticks in daily life

3. The low enthusiasm of the desire of the Dayak young generation to preserve chopsticks as a traditional Dayak traditional weapon actively with the revitalization of chopsticks and the values contained in them remain in accordance with the pace of the times.

\subsection{Restricting the problem.}

Problem limitation is needed so that the problems analyzed are more effective, efficient, directed and can be studied more deeply, while the problem limitation in this study is formulated as follows:

1. Making chopsticks as cendra mata for tourism purposes. In this way chopsticks are not only sustainable, but also can be a source of economic community

2. Making chopsticks as educational teaching materials, in subjects of local content (mulok). This way will arise awareness in students (tadidik peser) to preserve chopsticks.

3. Make the activity of choking as one of the contested sports branches, in the Regional Sports Week (PORDA) and the National Sports Week (PON). In this way, chopsticks will 
naturally be sustainable in the lives of the people (Dayak people). Note that for damak race purposes no poison can be killed

\subsection{Problems and Sub Problems}

A common problem in this study is "How to Preserve Chopsticks as a Typical Traditional Weapon of Dayak Protected High" (Study of Local Wisdom Documentation of Traditional Dayak Kalimantan Weapons). With the sub-problems in this study formulated in three substances as follows:

1. How to extract chopsticks as one of the eye cendra for tourism purposes.

2. How to make chopsticks as educational teaching materials, in subjects of local content (mulok).

3. How to make the activity of choking as one of the contested sports branches, in the Regional Sports Week (PORDA) or National Sports Week (PON).

\subsection{Research purposes}

This study aims to obtain objective information and clarity about: How to Preserve Chopsticks as a Typical Traditional Weapon of Dayak Protected High in Dayak Communities.

\subsection{Benefits of research}

The Benefits of Research in Preserving Chopsticks as Typical Traditional Dayak Protected Weapons are analogized into the following theoretical and practical conceptualizations:

1. Theoretical Benefits: Embed awareness of the younger generation, especially the younger generation of Dayaks, on the importance of preserving chopsticks as one of the nation's cultures, as well as being used as a weapon in sports competitions.

2. Practical Benefits: Chopsticks can be used as one of the eye cendra for the purpose of increasing interest in local tourism and education visits

\subsection{The scope of research}

1. Extract chopsticks as one of the eye cendra for tourism purposes.

2. Making chopsticks as educational teaching materials, in subjects of local content (mulok).

3. Make the activity of choking as one of the contested Sports branches, in the Regional Sports Week (PORDA) or National Sports Week (PON).

\subsection{Explanation of Terms}

In order for the terms used in research not to cause different interpretations between researchers and readers, it is necessary to explain the terms in this writing / research as follows: Chopsticks

Chopsticks are weapons used by Dayaks to hunt or in open battles or as a secret weapon for murder in silence in battle. The use of chopsticks is done by blowing. Chopsticks have their own advantages because they can be used as long-range weapons and do not damage nature because of its natural ingredients. 


\section{Damak or Eye Chopsticks}

The chopsticks are made with bamboo blades, palm sugar palm leaves or shingles which do have good quality. The material is then cut to a length of approximately $15 \mathrm{~cm}$ before it is taken so that the tip becomes pointed so that later it can be effective in stabbing enemies or game animals. use local ingredients.

\section{Poison Damak}

Damak poison comes from various dangerous plants and animals. The poison applied to damek is really made from dangerous materials. The first is the lumu or fruit of the typical Kalimantan lipu with the sensation of itching. This fruit's itching will not disappear even if it is scratched until the body's skin is peeled off. It is said that this fruit was used to repel plant pests, monkeys. Apart from luminous fruit there is also a tree of ipuh.

\section{Sangkoh}

Sangkoh or sangkur is a weapon that is bound or mounted on the tip of a chopstick made of iron which is tied tightly to the tip of a chopstick. Sangkoh is like a spear or a dagger, or another sharp weapon designed to be mounted on the muzzle of a long-barreled firearm. Sangkoh is used for self defense as a functioning weapon like a spear, which can be a melee weapon or the last defense weapon in battle

\section{Methodology of Research}

\section{Methods and Forms of Research}

1. Form of Research. Form of research In general, it is distinguished in several aspects. Some of these aspects include the purpose and the method aspects. Asfek Purpose refers to the expansion of science, usually referred to as basic research. Referring to problem solving and to get benefits for many people is generally referred to as applied research. Population and Sample $\mathrm{P}$

2. Population. Population is a generalization area consisting of objects / subjects that have certain quantities and characteristics determined by researchers to be studied and then drawn conclusions (Hamid 2014). The population in this study were traditional leaders, community leaders, indigenous Dayak leaders from various Dayak sub-tribes in West Kalimantan.

3. The Province of West Kalimantan, is one of the provinces in Kalimantan that has many Dayak tribes. Statistical data shows that in West Kalimantan have the most Dayak tribes. In just one district there were more than 30 Dayak tribes who had their own traditions and cultures, and were different from each other. The Dayak tribe is a Proto Malayu nation or one of the oldest tribes in Indonesia which has a Mongoloid race. The presence of the Dayak sub-tribes in West Kalimantan has many versions of the origin of its presence in Borneo. Statistically the number of Dayak sub-tribes in West Kalimantan reaches 211 sub-tribes. It is said that the number of Dayak sub-tribes in West Kalimantan is the largest sub-tribe in all of Kalimantan.

4. Samples. The sample is a portion of the number and characteristics possessed by the population or a small part of the population taken according to certain procedures so that it can represent the population. If the population is large, and researchers cannot learn all that is in the population, due to limited funds or costs, labor and time, the researcher can use 
samples taken from the population. (M.Nasir 2010). Samples to be taken from the population are truly representative or can represent the population. Considering the number of Dayak sub-tribes in West Kalimantan reached 211 sub-tribes, $10 \%$ of the total sub-tribes were drawn so that the population in the study was 21 people.

5. Data Collection Techniques and Tools

Data collection is an important step in research. The collected data is used as an analysis material both qualitatively and quantitatively. Therefore, data collection is carried out systematically, directed and in accordance with research problems. Data collection techniques are closely related to the research problems that will be solved. Therefore, the selection of techniques and appropriate data collection tools needs to be prioritized.

In this study data collection techniques and tools used and considered appropriate (appropriate) with the data to be collected are:

1. Direct communication techniques with interview guides as a data collection tool. Interviews were conducted with 21 traditional leaders who had been randomly assigned to get the right information from trusted resource persons. Interviews were conducted by submitting a number of questions from interviewers to 21 traditional leaders as resource persons. On the other hand the purpose of the interview is to get data from first hand (primary), as a complement to other data collection techniques, to test the results of data that has been collected.

2. The interview is a conversation with certain goals. In this method researchers and respondents face to face (face to face) to obtain information verbally with the aim of obtaining data that can explain the research problems of Lexy J Moleong (1991: 135). In this case the interviewer uses a tool in the form of a voice recorder. The tool is used to record an answer given from the speaker, so that it will not lose information that has been obtained in the field. After getting the recording, then the interviewer writes the question and answer transcript and then makes the data feasible as research information. The interview is a technique of collecting data by making communication with data sources. Such communication is carried out by dialogue (question and answer) verbally, both directly and indirectly (I.Djumhur and Muh.Surya, 1985).

3. The Oberbasi technique directly with the observation guide as a data collection tool. Observation was carried out on the activities of places of extraction and storage of curing devices such as at the Institute of Dayakology, Rumah Radank, traditional villages and traditional figures. spread in various regions spread across 14 City Regencies which in West Kalimantan Province are the object of research.

The purpose of observation is observing activities, followed by recording in sequence. This consists of several elements that appear in phenomena within the object under study. The results of the process are reported with a systematic and appropriate report (Nawawi and Martini 2008). Observation is an observation in which a case study or learning is done intentionally, directed, sequential, and according to the purpose. Recording on observation activities is called the observation results.

Documentation techniques with data collection tools in the form of recordings, videos, photo editing activities, in the form of Dayak devices and other official events that become activities of cursing. The purpose of documentation data collection of clogging activities is to find out the primary data directly from the place of activities of the clogging which is then 
prescribed in reflective narrative. Document study is a type of data collection that examines various kinds of documents that are useful for data analysis materials. Documents that can be used in data collection are divided into two, namely: Primary documents and secondary documents. Primary documents are documents that are directly obtained from activities such as chewing as carried out in Dayak device activities and others. Secondary documents are written documents or activities carried out by others based on reports, stories, pictures, photographs of cursing activities carried out by other people both in the form of biographies and in other forms.

The techniques and tools of data collection in the form of qualitative research use purposive sampling informants. The use of informants is done by purposive sampling, namely selection based on characteristics determined by the researcher. Data collection uses in-depth interviews (in depth interviews). Interviews conducted can be more than once for one informant. The process of data collection according to Creswell (2010) follows a zigzag pattern, namely researchers to the field seeking information, then analyzing the data obtained, returning to the field to get more information, analyzing data again, and so on.

Valid data is obtained by testing the validity of the data or testing the credibility of the research data. Data validity techniques are also used to extend observation in conducting discussions with colleagues. The extension of the observations in this study was carried out in the process of collecting data, the researchers visited / met with traditional leaders and actors who were used as objects / research subjects to build closeness, a sense of comfort and safety. Discussions with peers include giving unlimited advice, criticism and direction within the traditional leaders and trusted leaders of the Dayak community.

The steps taken in analyzing the data are as follows; (1) Data reduction (2) Data coding (3) Linking themes poured in narrative form (4) Data interpretation. The techniques and tools used for collecting data in this research are as follows:

\section{Observation technique.}

In this technique the researcher makes systematic observations and records of the research subjects. Based on the implementation, this observation technique is divided into:

a. Direct observation technique. In direct observation techniques, observations are carried out without using special equipment. The researcher immediately observes and records everything that is needed at the time the research process is carried out by the research subjects.

b. Indirect observation technique. In this technique, observations are made using certain equipment, such as a tape recorder. Observations in this case are carried out in actual or artificial situations, such as: roleplaying recorded with a camera.

c. c. Participatory observation techniques. In this technique, researchers take part in the real situation of the object of research. The researcher enters into a situation of observation and actively participates in activities within the system.

Direct Communication Techniques with tools in the form of interview guides.

The interview guide is prepared based on the effects of the research variables. The interview was aimed at 21 representatives of traditional leaders and leaders of the Dayak community who had been randomly determined by the researchers

Some things that are done before data collection in the field, are;

1. the type of data obtained,

2. data source,

3. how to collect data, and

4. Data needed. 
Based on sources, data can be divided into primary and secondary data. Primary data is information collected by researchers directly from the source. In this case, the researcher acts as a data collector. Primary data collection requires a long time and high costs. The advantages of using this primary data are more reliable and have high validity.

Secondary data, is information that has been collected by other parties. In this case the researcher does not directly obtain data from the source. The researcher acts as a data user. Secondary data is divided into two groups according to the source, namely: 1) Internal data, which is available at the place where the research is conducted, and 2) External data, namely data from external parties. The use of secondary data can save time, costs, and energy. However, the data obtained is not necessarily in accordance with the wishes or intent of the researcher, but is doubtful or unknown with certainty.

\section{Processing and Data Analysis}

\subsection{Research Location Profile (West Kalimantan)}

West Kalimantan is a province in Indonesia which is located on the island of Borneo with its capital Pontianak. The area of West Kalimantan Province is $146,807 \mathrm{~km}^{2}$ (7.53\% of Indonesia's total). It is the third largest province after Papua, and Central Kalimantan after the Province of East Kalimantan shares its territory with the North Kalimantasn Province. The West Kalimantan area is one of the regions that can be dubbed the "Thousand Rivers" Province. This nickname is in harmony with the geographical conditions which have hundreds of large and small rivers which among them can be navigated, for example the Kapuas river which is 1,144 $\mathrm{km}$ long. Some of the major rivers, including Kapuas refugees, are still the arteries and routes for inland transportation, although road infrastructure has been able to reach most sub-districts, the river still acts as a lifeline for the transportation of rural areas.

West Kalimantan borders land with neighboring parts of Sarawak, Malaysia. Although a small part of the West Kalimantan region is marine, West Kalimantan has dozens of large and small (partly uninhabited) islands scattered along the Karimata Strait and Natuna Sea which borders the Riau Islands Province. The population of the Province of West Kalimantan according to the 2016 census is $5,365,256$ people ( $1.85 \%$ of Indonesia's population).

Bakulapura or Tanjungpura was conquered by the Kingdom of Singhasari. Tanjungpura's territory stretches from Tanjung Dato to Tanjung Sambar. The ancient island of Borneo is divided into 3 main kingdom states: Borneo (Brunei), Sukadana (Tanjungpura) and Banjarmasin (Bumi Kencana). Tanjung Dato is the border of the Borneo mandala region (Brunei) with the mandala area of Sukadana (Tanjungpura), while Tanjung Sambar is the boundary of the mandala area of Sukadana / Tanjungpura with the mandala region of Banjarmasin (Kotawaringin area). The Jelai River, in Kotawaringin was under the control of Banjarmasin, while the Kendawangan river was under the authority of Sukadana. The border in the interior, the beginning of the Pinoh (Lawai) river basin, is included in the Kotawaringin Kingdom area (subordinate of Banjarmasin). The regions in West Kalimantan that were famous in ancient times include Tanjungpura and Batang Lawai. Loue (Lawai) by Tomé Pires is depicted in an area of a lot of diamonds, a distance from the Tanjompure four day cruise. Tanjungpura and Lawai are each led by a Patee (Patih). These masters were subject to Patee Unus, the ruler of Demak. [9] [10] Demak Sultanate has also been instrumental in helping the king of the Banjar Prince Samudera 
fight against his uncle Pangeran Tumenggung, the last ruler of the Kingdom of Daha, to fight for hegemony over the territory of South Kalimantan.

According to the texts of Hikayat Banjar and Kotawaringin, the land of Sambas, Sukadana and countries in Batang Lawai (the ancient name of the Kapuas river) had once been conquered by the Kingdom of Banjar having sent tribute since the Hindu era. The kingdom of Banjar named the kingdoms in West Kalimantan as the countries under the wind. The kingdom of Banjar has Dayak Biaju-Ot Danum and Dusun-Maanyan-Lawangan Dayak soldiers who often decapitate their enemies (ngayau). During the reign of King Maruhum Panambahan a Adipati Sambas / Panembahan Ratu Sambas had delivered tribute in the form of two large diamond seeds named Si Giwang and Si Misim. In 1604 the first time the Dutch traded with Sukadana. Since October 1, 1609, the Kingdom of Panembahan Sambas became a Dutch VOC protectorate.

The relationship of the kings of West Kalimantan with the Dutch VOC caused the anger of Sultan Agung, the king of Mataram Islam, so that he ordered Tumenggung Bahureksa to attack Sukadana in 1622. This situation caused tension throughout Kalimantan, to soften Mataram, the Sultanate of Banjar sent a mission to the Sultanate of Mataram. In October 1641 the mission of the Banjar Sultanate arrived in Jepara, the port of the Sultanate of Mataram by bringing diamond offerings from Si Misim (diamond separating themselves included Sanggau, Sintang and Lawai (Melawi Regency), while other areas belonged to the Banten Sultanate, except Sambas.

According to the deed of ladder March 26, 1778 the land of porcupines and Sukadana (mostly West Kalimantan) was handed over to the Dutch VOC by the Sultan of Banten. This is the area that originally belonged to the Dutch VOC in addition to the Sambas protectorate area. That same year Syarif Abdurrahman Alkadrie, who had been appointed in Banjarmasin as Prince, Prince Syarif Abdurrahman Nur Alam, was approved by the Dutch VOC as the first Sultan of Pontianak in the Dutch territory. In 1789 the Sultan of Pontianak was assisted by Kongsi Lan Fang ordered by the Dutch VOC to occupy the land of Mempawah and then conquer Sanggau. On May 4, 1826 Sultan Adam of Banjar handed over Jelai, Sintang and Lawai (Melawi Regency) to the Dutch East Indies colonial government.

Pads in 1846 the Dutch colony on the island of Borneo gained a special government as the Borneo Dependency. The west coast of Borneo consists of the assistant resident of Sambas and assistant resident of Pontianak. The Sambas Division covers the area from Tanjung Dato to the river mouth of the Doeri. While Pontianak division under Pontianak resident assistant covers Pontianak, Mempawah, Landak, Kubu, Simpang, Sukadana, Matan, Tayan, Meliau, Sanggau, Sekadau, Sintang, Melawi, Sepapoe, Belitang, Silat, Salimbau, Piassa, Jongkong, Boenoet, Malor, Parks, Ketan, and Poenan According to the Staatsblad van Nederlandisch Indië in 1849, 14 regions in this region were included in Wester-Afdeeling based on Bêsluit van den Minister van Staat, Gouverneur-Generaal van Nederlandsch-Indie, on August 27, 1849, No . 8. In 1855, the land of Sambas was entered into the territory of the Dutch East Indies into the Sambas Residency.

Based on the stories published by Malaysia, Brunei, and Singapore the areas that cannot be controlled from the Hindu kingdom to the Islamic sultanate in West Kalimantan are mostly from West Kalimantan such as Sambas State and its surroundings, and according to the State of Brunei Darussalam Hikayat Banjar is fake and not made from the Banjar Sultanate itself but from the hands that want to destroy the name of West Kalimantan and disseminated throughout Indonesia until now, because according to the research of psychologists in the world Sambas country has never been defeated and conquered by any country.

During the Dutch East Indies government based on the Governor General Decree contained in the 1938 STB No. 352, among others, regulating and stipulating that the capital of the administrative region of Gouvernement Borneo is domiciled in Banjarmasin, divided into 2 
Residentirs, one of which is Residentie Westerafdeeling Van Borneo with the capital of Pontianak which is headed by a Resident. On January 1, 1957 West Kalimantan officially became a stand-alone province on the island of Borneo, based on Law No. 25 of 1956 on December 7, 1956. The law also became the basis for the formation of two other provinces on the largest island in the archipelago. The two provinces are South Kalimantan and East Kalimantan Province.

\section{Natural Conditions of West Kalimantan}

West Kalimantan has a wet tropical climate, evenly distributed rainfall throughout the year with peak rainfall occurring in January and October the average temperature is between 26.0 to 27.0 and humidity averages between $80 \%$ and $90 \%$.

\section{Ethnicity}

Based on the 2010 census, the most dominant ethnic group was in West Kalimantan, namely the Dayak (49.91\%), then there was the Malay tribe (16.50\%). Dayak ethnicity is ethnic in rural areas, while ethnic Malays are the majority in coastal areas. The third largest ethnic group is Javanese $(8.66 \%)$ who have a settlement base in transmigration areas. In the fourth place are ethnic Chinese $(8.17 \%)$, many of which are in urban areas such as Singkawang and Pontianak. Next in fifth place is ethnic Madura (6.27\%) which has a settlement base in Pontianak and Kubu Raya. Ethnic is the sixth largest to ten, namely Bugis $(3.13 \%)$, Sundanese $(1.13 \%)$, Batak $(0.60 \%)$, Daya $(0.52 \%)$ and Banjar $(0.33 \%)$ and other tribes $(1.33 \%)$.

Table 1. Distribution of Tribes in Kalimantan

\begin{tabular}{rlcc}
\hline No. & Ethnicity & Total & Concentration \\
\hline 1 & $\underline{\text { Dayak }}$ & 2.194 .009 & $49,91 \%$ \\
2 & $\underline{\text { Melayu }}$ & 814.550 & $16,50 \%$ \\
3 & $\underline{\text { Jawa }}$ & 427.333 & $8,66 \%$ \\
4 & $\underline{\text { Tionghoa }}$ & 358.451 & $8,17 \%$ \\
5 & Madura & 274.869 & $6,27 \%$ \\
6 & $\underline{\text { Bugis }}$ & 137.282 & $3,13 \%$ \\
7 & $\underline{\text { Sunda }}$ & 49.530 & $1,13 \%$ \\
8 & $\underline{\text { Batak }}$ & 26.486 & $0,60 \%$ \\
9 & $\underline{\text { Daya }}$ & 22.690 & $0,52 \%$ \\
10 & Banjar & 14.430 & $0,33 \%$ \\
10 & Suku-suku lainnya & 58.306 & $1,33 \%$ \\
& Total & $\mathbf{4 . 3 8 5 . 3 5 6}$ & $\mathbf{1 0 0 , 0 0 \%}$ \\
\hline
\end{tabular}

West Kalimantan regional government data sources

\section{Language}

Besides the regional language Indonesian is a language generally used by the people of West Kalimantan. In addition, the liaison language, namely Pontianak Malay Language, Sambas Malay and Senganan Language according to the distribution area. Likewise there are various types of Dayak languages. According to the research of the Dayakology Institute of West Kalimantan there are 188 dialects spoken by Dayak tribes and Chinese languages such as 
Tiochiu and Khek / Hakka. The dialect meant by the language of the Dayak tribe is that there are so many similarities with the Malay language, only most are different at the end of words like makan (Melayu), makatn (Kanayatn), makai (Iban) and makot (Melahui).

Especially for the Uum Danum family, the language may be said to be independent and not a dialect of other Dayak groups. The dialect is in some sub-tribes of the Danum Dayak Uut themselves. As in the language of the Dohoi sub-tribe, for example, to say eating alone consists of at least 16 vocabulary words, ranging from the most refined to the most crude. For example, ngolasut (being smooth), germs (general), dekak (for the older or respected), ngonahuk (rough), monirak (most crude) and Macuh (for the spirits of the dead).

Malay in West Kalimantan consists of several types, including Pontianak Malay and Sambas Malay Language. Pontianak Malay language itself has the same accent as Sarawak Malay, Malaysian Malay and Riau Malay.

\section{Religion and Tribe}

The majority of the people of West Kalimantan adhere to Islam (55.68\%). The majority of Muslim areas in West Kalimantan are coastal areas which are predominantly inhabited by Malays such as Sambas, Mempawah, Ketapang, North Kayong, Kubu Raya, Kapuas Hulu and Pontianak City. In Melawi Regency and Singkawang City about $49 \%$ of the population are Muslim. Islam is also embraced by Javanese, Madurese and Bugis tribes in West Kalimantan.

In rural areas inhabited by Dayaks, the majority of the population are Christian (Catholic / Protestant), such as in Bengkayang, Landak, Sanggau, Sintang and Sekadau Regencies. The Chinese in West Kalimantan are mostly Buddhists and Christians (Catholics / Protestants). In areas where there are many Chinese ethnic groups such as Singkawang City and Pontianak there are also large numbers of Buddhists.

\subsection{Research and Discussion Results}

Based on the results of data analysis it is known that Chopsticks or blowpipes (sipet) are weapons used for hunting and open fighting and as a secret weapon for murder silently. The use of chopsticks is blown. The use of chopsticks has its own advantages because it can be used as a long-range weapon and does not damage nature because of its natural ingredients. And one of the advantages of this chopstick has a shooting accuracy that can reach 200 meters.

Chopsticks as a weapon for the Dayaks

Many indigenous people have chopsticks, for example in the Indonesian Dayaks and indigenous tribes in South America. Chopsticks are usually tube-shaped which allows a small arrow to be shot shot towards the target. In Japan, Chopsticks, called fukiya, are used by samurai as weapons to kill enemies whose chopsticks are poisoned with poison from puffer fish.

According to the story of the Dayak elders / figures in the colonial period in Kalimantan, the Dutch soldiers were armed with rifles with the latest technology of their time, while Dayak soldiers generally only relied on chopsticks. However, Dutch soldiers were far more afraid of being hit by chopsticks than Dayak soldiers were hit by bullets. What made the trembling invaders a poison chopstick child. Before leaving for the battlefield, Dayak warriors smear the eyes of chopsticks with the sap of the tree or the tree iren. In silence, they act to release the chopsticks called damak.

\section{Chopsticks Structure}


Traditional chopsticks consisting of bamboo tubes can also be made from wood that is 1-3 $\mathrm{m}$ in length, Chopsticks are equipped with chopsticks with round shapes of approximately less than $1 \mathrm{~cm}$ in diameter. Chopsticks (damak) can be made of bamboo with one cone shaped made of wood with a light mass. This works so that chopsticks can go straight and balance when released from the reed. While the other end is pointed and is usually given a very deadly poison. Toxins are made from the sap of forest plants and until now there is still no antidote. Chopsticks are used by blowing. The strength of the breath of the clipper will determine how far the distance between the chopsticks can accelerate to the target

\section{Chopsticks and Chopsticks}

The base of the chopsticks is usually larger and in this part the chopstick child is inserted and then blown. Between chopsticks and chopsticks have a high dependency (mutual support). Althoughthe reed is good but if the chopstick child is made carelessly the results are also less satisfying and vice versa. This means that the two are important to each other in the accuracy of the target / prey even though clogging breath and proficiency are also very important here.

To achieve the right target and strong breathing, the length of chopsticks must match the height of the person using it, the most important part of the blowpipe, other than the chopsticks, is the bullet or chopsticks called damak. The tip of the chopstick child is pointed, while the back base is given a kind of cork and a kind of tree branch so the chopsticks drift when they reach the target. Poisonous damek by ethnic Lundayeh Dayaks is called parir. This very deadly poison is a mixture of various tree sap, herbs and "can" animals such as snakes. children sumit there are various forms, one of which is "Langan Adang" (Flying Bullets) This chopstick child is used to chew a game that is far or high, the shape is unique with leaves on the back of a chopstick child. These chopsticks can reach between 50 and 70 meters. scorpion.

\section{Chopsticks as a sport}

In modern times the function of chopsticks is no longer for hunting or for war but is contested in regional sports. Become a sports number that is taken into account in every match held in the Regency / City. Chopsticks sports are not much different from other sports such as shooting or arrow sports. Usually the target is made of circles from cardboard or paper. Contest participants compete for the circle that has been made at a distance determined by the competition committee.

\section{Making Chopsticks}

In the process of making chopsticks, it is done in two ways, namely the first hand skill from the maker. The second way is by using energy from nature by utilizing the power of the cascade of water that is made into a kind of rice pounder. According to the belief of the Dayak tribe of chopsticks or sipets this should not be used to kill others. Chopsticks can only be used for daily needs, such as hunting. Chopsticks are also not trampled upon, let alone cut with machetes because if this is done it means violating customary law, which can result in the perpetrators being prosecuted in the adat meeting.

The struggle of the Dayak tribe against the Dutch colonialists was no less heroic than the fighters who were said to use pointed bamboo to liberate the Indonesian people. Chopsticks are one of the typical weapons that can become an unforgettable part of history. So, at this time, the skills of chewing are no longer for hunting or for war, but are competed in regional sports. Become a sports number that is taken into account in every match held in the region. Chopsticks sports are not much different from other sports such as shooting or arrow sports. Usually the 
target is made of circles from cardboard or paper. Contest participants compete for the circle that has been made at a distance determined by the competition committee.

\section{Chopsticks Weapons of Pride for the Dayaks}

Dayak tribes recognize various kinds of weapons that are commonly used for hunting and fighting in ancient times, or for daily use such as in fields. For example blowpipe, mandau, lonjo (spear), shield (telawang), and spurs. The blowgun weapon is a weapon of pride and a major weapon for the Dayak community.

There is no antidote to the blowpipe poison until now, whether it's modern medicine. Armed chopsticks in the form of reeds from round logs of 1.9 meters to 2.1 meters. Chopsticks must be made of hard wood such as ironwood, look, leaf, berangbungkan, rasak, or plepek wood.

The diameter of chopsticks is two to three centimeters in diameter in the center, with a hole diameter of about one centimeter. This hole is for entering chopsticks or damak children.

Traditionally, if you want to be right on target and strong to breathe using chopsticks, the length of chopsticks does not exceed the height and the person using it. The method of making chopsticks, such as ulin hardwoods that are still in the form of beams measuring $10 \times 10$ centimeters with a predetermined length are hung vertically somewhere. Then the bottom of the beam is drilled upwards. "The goal is that the rest of the drilling will immediately fall to the ground. So, there is no need to bother cleaning the drilling holes, and usually this way the drilling results are more straightforward,".

After being drilled, the perforated beam is crushed (rotated) so that it is round like a pipe. After that, accessories are attached. The base of chopsticks is usually larger than the chopstick muzzle. At the end of the muzzle is a spear made of iron or mountain rock called sangkoh. The usefulness of this Sangkoh is to reserve weapons when binate which is used as a target aid. Both of these devices are placed opposite each other at the tip of the chopstick muzzle.

The most important part of the blowpipe, besides the chopsticks, is the bullet or chopsticks. Chopstick children, also called damak. The tip of the chopsticks is pointed, while the back of the chopper is a kind of cork from a kind of tree branch so the chopsticks drift when they reach the target. For race purposes, damek is not given poison like chopsticks for hunting. Chopstick children to fight or hunt are usually given keratan along about three centimeters at the end of a chopstick child with the intention that the tip is broken and left in the hunted body until the poison works faster.

To put chopsticks in a special container called telep. Made from one bamboo segment carved and tied with rattan and given a lid, a telepath can save around 50-100 chopsticks. Poison damek by the sub-ethnic Dayak Lundayeh is called parir. This very deadly poison is a mixture of sharing tree sap, herbs and animals such as snakes and scorpions. The sap of the tree used for poisons includes the sap of the wood, the wood siren, or the upas, mixed with the sap of the uwi ara wood, or the sap of toba. Can animals, such as snakes, will strengthen the effects of this poison. According to Barnabas, until now there has been no bidder for the poison of chopsticks that have entered the blood vessels. "In the Dayak community there is no known antidote for chopsticks," he said. Strangely, even though it is very toxic, game meat is safe to eat. "Hunting for the meat is to be eaten. However, even though the poison of chopsticks is very strong, we are safe to eat the meat of the game, even if we lick the poison it is actually fine," said one of the Dayak figures (Barnabas). However, if the damak poisons go straight into the blood, humans or all animals will die soon. "

Sjumpit if it will be used for hunting or fighting, it must be kept away from odors, for example the smell of perfume or perfume, soap, shampoo and the like. Besides being poisonous, the advantages possessed by this weapon, compared to other typical Dayak weapons, are the ability to hit targets within relatively far distances. Effective distance can reach tens of meters, 
depending on the ability of the chopper. In addition, chopsticks also do not cause noise. This silent element is very important when targeting enemies and game animals who are off guard.

There are certain techniques and training is needed so that one can be skilled and smart to hunt using chopsticks. How to take breath and body position must also be considered. How to hold the correct chopsticks, both palms must face up. both hands should be close together or touching. In addition to the use of hunting and warfare, other uses of chopsticks are for traditional ceremonies or as dowry in traditional Dayak weddings. "When engaged, chopsticks can also be used as dowry," (Barnabas).

\section{Chopsticks as a symbol of pride of the Dayaks}

Chopsticks are one of the typical weapons that are often used by Dayak tribe. In addition to hunting, chopsticks are a tool of war. In terms of the use of chopsticks has its own advantages because it can be used as a long-range weapon and does not damage nature because of its natural ingredients. And one of the advantages of chopsticks or slugs has firing accuracy that can reach 218 yards or around 200 meters. Seen from the shape of chopsticks, chopsticks have a round shape and have a length of 1.5-2 meters, about 2-3 centimeters in diameter. At the end of chopsticks aiming targets such as small shells like diamonds measuring 3-5 centimeters are processed. In the middle of the chopsticks are hollowed out as the entry point for damek (chopsticks). In the upper part of the chopstick, more precisely at the front of the aiming target, a spear or sangkoh (in Dayak language) is installed. Sangkoh is made of mountain stone which is then tied with UAE woven (rattan).

The types of wood that are usually used to make chopsticks in general are wood, ironwood or tabalien, plepek wood, and resak wood. Not to forget also tamiang or lamiang, which is a type of bamboo that is small in size, has a long, hard, and poisonous base. Not everyone has the expertise to make chopsticks or slugs. There are only a few tribes on the island of Borneo that have expertise in making chopsticks, namely the Ot Danum, Punan, Apu Kayan, Bahau, Siang and Dayak Pasir tribes.

In the process of making chopsticks, it is done in two ways, namely the first hand skill from the maker. The second way is by using energy from nature by utilizing the power of the cascade of water that is made into a kind of rice pounder. The selling price of chopsticks or sipet has been determined by customary law, which is equal to jipen ije or due date.

In colonial times in Kalimantan long ago, Dutch soldiers armed with rifles with the latest technology in their time, while Dayak soldiers generally only rely on chopsticks. However, Dutch soldiers were far more afraid of being hit by chopsticks than Dayak soldiers were hit by bullets. What made the trembling invaders a poison chopstick child. Before leaving for the battlefield, Dayak warriors smear the eyes of chopsticks with the sap of the tree or the tree iren. In silence, they act to release the chopsticks called damek.

Without knowing the whereabouts of his opponent, suddenly one by one the Dutch soldiers lay, making the rest of his surviving colleagues run away. Even if he had the chance to retaliate with a shot, the impact of hot tin turned out to be far out of balance with the enormity of poisonous chopsticks. Less than five minutes after the chopsticks were stuck on any part of the body, the Dutch soldiers who were initially seizures would be killed. In fact, it could be that in seconds they are lifeless. Meanwhile, if the Dayak soldier is shot and not in an important part, the bullet will be removed. After being treated a few weeks, they are ready to fight back. The struggle of the Dayak nation's children against the Dutch colonizers turned out to be no less heroic than the fighters who were said to use pointed bamboo to redress the country of Indonesia. Chopsticks are one of the unique weapons capable of being an unforgettable part of history. So that now, the skills to chew into sports are popular in the Kalimantan region. 


\section{Dayak Tradition Chopsticks Become Sports}

According to records at Tempo. Pontianak - Chopsticks, very closely related to the Dayak culture. In ancient times, chopsticks were used by Dayak tribesmen to hunt and fight. Dayak men in ancient times, must be able to chew properly. The expertise is used as a marker, a man is late through the teenage phase. The chopsticks competition, which was held at the Dayak Weekend, became a place to preserve chopsticks to the Dayak young generation. Times and technology are feared to erode chopsticks from civilization.

\subsection{Discussion of Research Results}

\section{Chopsticks}

Chopsticks are cutlery originating from East Asia, in the form of two long wooden sticks held between the fingers of one hand. Chopsticks are used to clamp and move food from the container, from one plate to another or put food into the mouth. Chopsticks can be made from materials such as bamboo, metal, ivory and plastic whose surface has been smoothed or coated with a coating material such as varnish or paint so as not to hurt the mouth and look good.

Chopsticks are used in many countries around the world to enjoy East Asian specialties. In some Southeast Asian countries, chopsticks are a tool main meals are as important as spoons and forks. In Indonesia, a choice of spoons or chopsticks is provided at restaurants that provide Chinese, Korean cuisine, Japanese cuisine, Vietnamese cuisine, Thai cuisine to the seller of meatballs or dumpling noodles on the roadside.

The quality of the material and the shape of chopsticks can vary, but chopsticks generally consist of a pair of short and straight sticks that have the same length. At the base of chopsticks are sometimes decorated with decorative motifs or interesting images so that the pair of chopsticks is not interchangeable. Ornaments at the base of chopsticks also function as a differentiator between the base and the tip of the chopstick. The tip of chopsticks is used to clamp food when the fingers hold the base of the chopstick.

\section{Making Chopsticks}

Making chopsticks is done in two ways, namely the first hand skill from the maker himself. The second way, by using energy from nature, is by utilizing the current "water cascade" of the river which is made into a kind of rice pounder. Chopsticks are not allowed or abstained from being trampled on, let alone cut with machetes because if this is done it violates customary law, which can cause the culprit to be prosecuted in a traditional meeting.

Chopsticks consist of three parts. The first part is blowpipe rod. The blowpipe is made of wood in the shape of a long sphere with a hole in it with a diameter of about 3-3.5 cm and a diameter of 1-1.2 cm. For chopsticks, wood used from selected types such as Bunyau, Penyauk ', Kebaca and Tapang wood. The size of the blowpipe rod is usually adjusted to the owner of the blowpipe itself, which is about one and a half meters long. The other part is, Mata Tombak (bu'bulis) which is made of steel, 20-30 cm long. While the next part is Iron for target scouts (header). The ribbon head is made of iron and is tied to the opposite side of the spear eye and at the end protrudes parallel to the chopstick rod. Its function is as a benchmark for the focus of the intended target.

\section{Chopsticks and Chopsticks}


The base of chopsticks is usually larger and in this part the chopstick child is inserted and then blown. Between chopsticks and chopsticks have a high dependency (mutual support). Even though the reed is good but the chopsticks are carelessly made the results are also less satisfying and vice versa. This means that the two are important to each other in the accuracy of the target / prey even though clogging breath and proficiency are also very important here.

\section{Chopsticks Rod}

Chopsticks are shaped like pipes. Made of hard round wood, such as ironwood, lanan, and other wood. The common length of the chopsticks is around 2 meters. But for professional users, the length of the Chopsticks is made as high as the user's body. This is believed to make the user breathe and shoot right on target. Chopsticks stem diameter between 2-3 cm. In the middle it is given a hole with a diameter of about $1 \mathrm{~cm}$. In this hole the chopstick child who was the bullet was placed.

\section{Chopstick Children (Damak)}

Children Chopsticks, called Damak, are single pointed and sharp needles. The needle is inserted into a cork-like cushion that is given bird feathers so that chopsticks can float constantly towards the target. At the tip of the needle is given a variety of very deadly poisons, which are made from various tree sap, herbs, and animal poisons such as snakes, scorpions and green frogs. If it is blown by an expert, the chopsticks can be shot more than 100 meters in a constant straight direction.

\section{Chopsticks As Sports Equipment}

The function of chopsticks is not to hunt or to fight, but to compete in regional sports. Become a sports number that is taken into account in every match held in the region. Chopsticks sports are not much different from other sports such as shooting or arrow sports. Usually the target is made of circles from cardboard or paper. Contest participants compete for the circle that has been made at a distance determined by the competition committee. In Japan chopsticks are fostered by the International Fukiyado Association (IFA).

"Chopsticks used to be used as a hunting and fighting tool, along with the development of chopsticks can be used as a means to attract domestic and international tourists, through a competition. "Sumpit has groups and community groups, from this community can develop in its development, facilities and infrastructure, through exhibition competitions like this and create reliable, and attractive chopstick players, tourists,"

Traditional weapon chopsticks are typical of the Dayak tribe which are commonly used by Dayak tribes since time

Kalimantan Dayaks are not the only ones using chopsticks as weapons, tribes native to South America and Japanese Samurai are said to also use chopsticks for their shapes and appearance. The Dayaks do not only use chopsticks as weapons, but they also use mandau (swords / machetes), lonjo (spears), and telawang (shields)

\section{Closing}

\subsection{Conclusion}

Based on data analysis and presentation of the data described in the previous section, it can be concluded in general that the preservation of Chopsticks as Typical Dayak Traditional 
Weapons has not been carried out optimally. Young Dayak generations who live in this millennium tend not to be interested in something "traditional" because they are considered outdated. Specifically, it can be concluded as follows:

1. Pelistarian chopsticks as one of the eye cendra for tourism purposes have not materialized well. Chopsticks crafters as one of the souvenirs tend to be done by young people (people) outside of Dayak people. In shops, in the market-passar and at the airport there have not been found Dayaks (Dayak youth) who work as entrepreneurs and sellers of chopsticks as eye cendra.

2. Making chopsticks as educational teaching materials, in subjects of local content (mulok) seems still far from expectations. Making chopsticks as educational teaching materials, in local content subjects is collided with the curriculum that supports them. Admittedly there is a local content curriculum, but the supporting facilities are minimal. Like no / no teacher who deserves a representative to be the teacher. On the other hand, Dayak students and children who should receive these lessons are spread in various schools, which are relatively far apart with the addition of little iturelative lessons, except in remote schools.

3. Making the activity of choking as one of the contested sports branches, in the Regional Sports Week (PORDA) or the National Sports Week (PON) is highly dependent on the authority of the local Government, especially the authority of the Education Office. It is very possible to make the activity of choking as one of the contested branches of Sports, in the Regional Sports Week if the schools synergize with the Office of Education and supported by the school committee and the education council who love local culture as one of the national cultural riches.

\subsection{Suggestions}

1. Pelistarian chopsticks as one of the eye cendra for tourism needs need to be implanted early on to the younger generation (Dayak) especially as a local culture that promotes national culture. School leaders, the Education Office can collaborate with Kopersi and UMKM institutions as makers and suppliers to retail shops / eye cendra in various cities

2. Making chopsticks as educational teaching materials, in subjects of local content (mulok) is still far from expectations. Therefore, it is suggested that non-formal education such as courses, social workshops and forms of non-formal educators can synergize to strive for, train, the young generation (Dayak) especially to disseminate the importance of preserving the local culture. Dayak elders, Dayak figures and Dayak intellectuals are not ignorant of the preservation of local culture as one of Indonesia's national / national cultures

3. The Government Authority through the Education Office and school leaders has the role to determine the activities of cackling as one of the contested Sports branches, in the Regional Sports Week (PORDA) or National Sports Week (PON). Dayak leaders need to play an active role in collaborating with education authorities to harmonize chopsticks as sports as a preservation of national culture.

\section{Reference}

[1] Administrative-sub-divisions-in-Dutch-Borneo, -ca (1879) (Netherlands) Staatsblad van Nederlandisch Indië, s.n., 1849 
[2] Ansar, Rahman. (2000) Establishment Perspective of Pontianak City. Pontianak: Without Publishers.

[3] Central Bureau of Statistics (BPS) (2005) BPS of West Kalimantan Province, West Kalimantan in Figures, 2014 - 2015; 2016 - 2017 Pontianak Central Bureau of Statistics

[4] Bakker H, P.A. (2014) Sanggau's history. Het.Rijk. Translated Father Yeremias OFM. Cap. Published by the Office of Culture and Tourism. Sanggau District Government.

[5] Brenda, Dorn Conard. (1988) Cooperative Learning and Prejudice Reduction. USA: Social Studies Journal. Aplir / May.

[6] Danang at most Indonesia.scomhttp: //blogsauted.blogspot.co.id/2012/12/ chopsticks-weapons-hunting-at-once.html \# ixzz5Eii72VOw.

[7] Culture and Tourism Service of West Kalimantan Province - History of the Kingdom of Tayan Excerpt from the history book of Adat and Istiad in West Kalimantan, J.U.Lontan

[8] Hasanuddin (2013) Pontianak Colonial Period. Waves Publisher Yogyakarta

[9] Helius Sjamsuddin (2014) Change in West Kalimantan Sintang Kingdom 1822-1942

[10] Lontaan, J.U. (1975) History, Customary Law, and Customary Kalimantan-West Customs. Pontianak: Pilindo.

[11] Jarolimek, John. (1967) Social Studies in Elementary Education. 5th. edition. NY: McMillan Co. Inc.

[12] Kompas.com "Dayak Chopsticks are more feared than bullets", https: // regional. kompas.com/read/2011/06/02/14431016/ Chopsticks. Dayak. More. Feared. From. Bullet.

[13] Kompas.com "Difficult-Making-Traditional-Chopsticks", https: //internasional.kompas kompas.com/read/2011/06/02/18400750/Sulit.Pembuatan.Sumpit. Traditional

[14] Muhammad Natsir, Sos.M.Si History of West Kalimantan Pontianak: Without Publisher.

[15] National Education System Law No.20 of 2003; Balitbang Depdiknas Jakarta

[16] Truhart P., Regents of Nations. Systematic Chronology of States and Their Political Representatives in Past and Present. A Biographical Reference Book, Part 3: Asia \& Pacific Oceania, Munich 2003, s. 1245-1257, ISBN 3-598-21545-2.

[17] Veth, P.J. (1854) Borneo“ Wester Afdeling. Zaltbommel: Noman en Zoon.

[18] Weiner, B. (1979) Theory of Motivation for Some Classroom Experiences, Journal of Abnormal Psychology, 71, 1-12

[19] Weiner, B. (1986) Attribution Theory and Attribution Therapy: Some Theoritical Observation and Suggestions. British Journal of Clinical Psychology, 27, 93-104.

[20] Weiner, B. (1990) History of Motivational Research in Education, Journal of Personality and Social Psychology, 55, 738-748

[21] Yacobus.S.E. Frans..L.BA (2014) Pangsuma War History Majang Desa. Second print. Publisher of Sanggau Regency Culture and Tourism Office. Sanggau District Government

[22] Yus Suhardi et al. Sanggau from the Period to the Second Period The Publisher of the Sanggau District Culture and Tourism Office. Sanggau District Government. 